\title{
Minireview
}

\section{Tissue-selective therapy of cancer}

\author{
MV Blagosklonny*,I \\ 'Department of Medicine, New York Medical College, Valhalla, NY 10595, USA
}

Instead of exploiting the differences between normal and cancer cells, seemingly unrelated anticancer modalities (from immunotherapy to hormones) exploit (a) the differences between various normal tissues and (b) tissue-specific similarities of normal and cancer cells. Although these therapies are successfully used for years to treat leukaemia and cancer, their unifying principles have never been explicitly formulated: namely, they are aimed at differentiated cells and normal tissues and target both normal and cancer cells in a tissue-specific manner. Whereas tiny differences between cancer and normal cells have yet to be successfully exploited for selective anticancer therapy, numerous tissue-specific differences (e.g. differences between melanocytes, prostate, thyroid and breast cells) provide a means to attack selectively that exact tissue that produced cancer. Despite inherent limitations, such as fostering resistance and dedifferentiation, tissue-selective therapy have enormous potentials to control cancer. British Journal of Cancer (2003) 89, I|47- I I5I. doi:I0.1038/sj.bjc.660 I 256 www.bjcancer.com (C) 2003 Cancer Research UK

Keywords: cancer; tissue; therapy; immunotherapy; hormones; resistance

As Robert Weinberg accurately pointed out, 'virtually all the proteins made by cancer cells are normal proteins' (Dickey, 2002). What is then a basis for immunotherapy of cancer? How immunotherapy can possibly work, if cancer cells do not provide a cancer-specific protein. What are these mysterious tumourspecific antigens? The answer is startling. For example, the melanoma-derived protein (a target of anticancer immunotherapy) turned out to be a normal (melanocyte-differentiation) antigen (Wang et al, 1996). So, it is not a cancer-specific protein, which is absent in normal cells, but a tissue-specific protein that is shared by both normal and malignant melanocytes. Even further, malignant melanocytes tend to lose tissue-specific proteins (dedifferentiation) rather than to acquire them. Many tumour antigens are normal tissue-differentiation antigens (Overwijk et al, 1999; Overwijk and Restifo, 2000). Consequently, immunisation with these 'self' antigens could induce autoimmunity. Vaccine strategies targeting tissue differentiation antigens may be valuable in cancers arising from nonessential cells and organs such as melanocytes, prostate, testis, breast, and ovary (Overwijk and Restifo, 2000). Thus, 'anticancer' immunotherapy is directed against normal differentiation antigens.

Yet, it is more difficult to control the immune response than to administer small molecular therapeutics. Can therapeutic agents be designed in a tissue-specific fashion, to attack normal differentiated cells? And is tissue-specific therapy applicable not only to 'non-essential' tissues such as breast and prostate but also to vital tissues such as lymphoid and thyroid. A therapy that is aimed at 'something' unique for a particular tissue (Figure 1). It may be a unique cellular biochemical activity (production of melanin or uptake of iodine). It may be an antigen or an enzyme.

* Correspondence: Dr MV Blagosklonny, Brander Cancer Research Institute, New York Medical College, 19 Bradhurst Ave, suite 2400, Hawthorne, NY 10532, USA; E-mail: M_Blagosklonny@NYMC.EDU Received 16 April 2003; revised 25 June 2003; accepted 8 July 2003
Or cell dependence on hormones... . For example, normal prostate epithelial and testicular cells selectively depend on androgens for survival and proliferation.

\section{HORMONAL THERAPY IN PROSTATE CANCER}

Normal prostate epithelial cells depend on androgens for their growth and survival. For example, androgen ablation induces apoptosis of prostatic glandular cells. In 1941, it was discovered that the initial growth of prostate cancer is dependent on androgens. Androgen suppression (in the form of medical or surgical castration with inhibition of adrenal androgens) became the standard primary treatment for advanced prostate cancer. Antiandrogen therapy causes regression of prostate tumours in more than $80 \%$ of patients with metastatic disease (Reese, 2000).

During the course of prostate cancer progression, however, cells convert from an androgen-dependent to an androgen-independent (Craft et al, 1999; Feldman and Feldman, 2001). Following androgen suppression, recurrent prostate carcinomas are able to avoid apoptosis (Koivisto et al, 1997). Prostate cancer cells can acquire the ability to grow without androgens by suppressing the apoptotic machinery or by using growth factors and steroids other than androgens (Feldman and Feldman, 2001). Following antiandrogen therapy, almost half patients experienced a second relapse heralded by a rise in the serum prostate-specific antigen (PSA). Tumour progression on hormonal therapy is a surrogate for impending cancer patient death (Zietman et al, 1996). Once a relapse occurs following primary endocrine treatment, metastatic prostate cancer is one of the most therapy-resistant human neoplasms (Zietman et al, 1996).

In summary, antihormone therapy has an excellent response $(80 \%)$ but, on the other hand, promotes hormone-independent disease, which is aggressive and resistant. By killing cancer cells having a tissue-specific characteristic (e.g. hormone-dependence), tissue-selective therapy causes remission but also selects for resistant cancer (Figure 2). 
Tissue 1
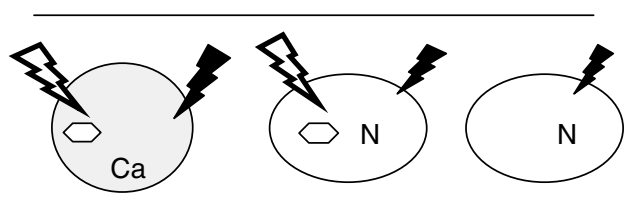

Therapeutic effects
Tissue 2

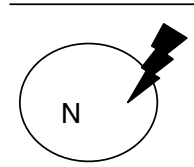

Side effects

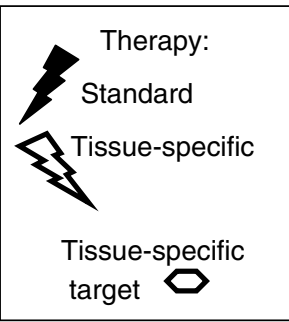

Figure I Tissue-selective and standard anticancer therapies. Standard therapy that preferentially targets proliferating cells causes side effects by targeting an essential tissue (tissue 2). Tissue-selective therapy targets cancer cells (Ca) and sub population of normal cells of the same tissue, with low side effects.
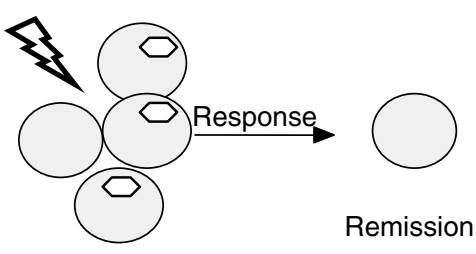

Remission

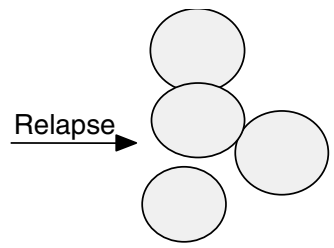

Initial tumour

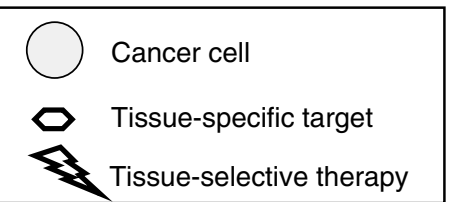

Figure 2 Tissue-selective therapy: from remission to relapse. By killing cells with tissue-specific targets (or traits such as hormone-dependence), tissue-selective therapy causes clinical response (remission). Cancer cells lacking tissue-specific targets survive, leading to relapse. Once relapsed, cancer is likely to be resistant to this therapy.

\section{EXPERIMENTAL PSA-DIRECTED THERAPY IN PROSTATE CANCER}

Loss of one tissue-specific trait (e.g. hormone-dependence) is not necessarily associated with loss of other traits (e.g. expression of PSA, a normal prostate-specific protease). Therefore, PSA is an attractive target of tissue-specific therapy. For example, a peptidedoxorubicin 'prodrug', which is cleaved and activated by PSA, selectively kills prostate tumour cells in vivo (DeFeo-Jones et al, 2000).

\section{ANTIHORMONAL THERAPY IN BREAST CANCER}

The breast is a target organ for oestrogens and progesterone, which control several functions of the normal and abnormal mammary epithelium. As demonstrated by postmenopausal hormone replacement therapy, oestrogens plus progestines induce proliferation of breast epithelial cells localised to the terminal duct-lobular unit of the breast, which is the site of development of most breast cancers (Hofseth et al, 1999). Treatment with antioestrogens (e.g. tamoxifen) is the first-line therapy of oestrogen receptor (ER)-positive cancer, both for metastatic disease and after mastectomy. Two-thirds of the patients with metastatic breast cancers respond to tamoxifen (or toremifen) with positive tumour regression for an average of 12-18 months. Another 20\% have prolonged stable disease lasting for at least 6 months. Patients who benefited most were postmenopausal and had tumours strongly positive for both ER and progesterone receptor (Osborne et al, 2000). In adjuvant therapy after surgical treatment of nonmetastatic cancer, there was $50 \%$ reduction of the odds of recurrence of breast cancer.

Like other tissue-selective therapies, antioestrogens (e.g. tamoxifen) are remarkably nontoxic. Therapeutic plasma concentrations of tamoxifen are dozens times less than its maximally achievable concentrations, which is $3-8 \mu \mathrm{M}$ (Bergan et al, 1999). Despite the initial benefits of tamoxifen, most patients eventually relapsed (Figure 2). Furthermore, such tamoxifen-resistant tumours may be stimulated by tamoxifen and, in contrast, suppressed by oestrogens (Song et al, 2001). This potentially might be exploited for 'withdrawal' therapy in breast cancer. Similarly, in prostate cancer, intermittent androgen blockade appears to be a potential alternative to permanent androgen blockade (Wolff and Tunn, 2000).

\section{GLUCOCORTICOID IN LEUKAEMIA}

Glucocorticoids and synthetic steroids (dexamethasone, prednisolone) suppress functions, prevent proliferation, and induce apoptosis in both $\mathrm{T}$ and $\mathrm{B}$ lymphocytes. Even during physiological stress, glucorticoids can kill $\mathrm{CD} 4(+)$ and $\mathrm{CD} 8(+)$ thymocytes (Ashwell et al, 2000). In addition to T lymphocytes, glucocorticoids induce apoptosis in B cells, pre-B and immature B cells, which is inhibited by Bcl-2 (Merino et al, 1994). Bcl-2 is highly expressed in $\mathrm{B}$-cell precursors (pro-B cells) and mature B cells, but is low at the pre-B and immature B-cell stages of development (Merino et al, 1994). High levels of Bcl-2 and Bcl-x render intestinal intraepithelial lymphocytes resistant to apoptosis by glucocorticoids (Van Houten et al, 1997). Glucocorticoids-induced-apoptosis in cells of the lymphoid lineage at certain stages of differentiation has been exploited to a great extent in the therapy of malignant lymphoproliferative disorders. For example, glucocorticoids are included in almost all treatment regimens for childhood acute lymphoblastic leukaemia (ALL). Leukaemic blast sensitivity to glucocorticoids correlates with sensitivity to chemotherapeutic agents and with outcome after multiagent therapy (Kaspers et al, 1998).

Effect of glucocorticoid therapy is, however, hampered by the occurrence of resistant clones evolving under selective glucocorticoid pressure. At relapse, loss of sensitivity to glucocorticosteroids is common and out of proportion to the loss of sensitivity to other agents. Mechanisms of glucocorticoid resistance involve downregulation of glucocorticoid receptor, mutant receptor, abnormal HSPs expression, and inactivation of apoptotic pathways (Tissing et al, 2003).

We can generalise that tissue-selective therapy inevitably selects for resistance (Figure 2). Another lesson of glucocorticoid therapy is that tissue-selective therapy may target vitally important tissues, namely, the lymphoid system, without dose-limiting side effects. Of course, immunosuppression is an unavoidable side effect. Also, glucocorticoids cause nonlymphoid side effects, which, in theory, can be avoided by substituting glucocorticoids with antilymphocyte antibodies. Antibodies can deliver toxins and radioactivity (Allen, 2002; Frankel, 2002).

We suggest that, in essential tissues (e.g. the immune system), side effects could be further decreased by targeting cell subpopulation that originated a malignant clone (a subtissueselective therapy). Immunotherapy of leukaemia provides examples. 


\section{TISSUE-SELECTIVE IMMUNOTHERAPY IN LEUKAEMIA}

Antibody-based therapy is intended to target leukaemia cells selectively. In reality, it targets tissue-specific antigens. Several dozens of surface antigens, referred to as CDs, are expressed on normal lymphoid and myeloid cells. Two monoclonal antibodies, rituximab (anti-CD20) and Campath-1 H (anti-CD52), are widely used. Rituximab is active in follicular non-Hodgkin's lymphomas and in chronic lymphocytic leukaemia (CLL) with response rates of $50 \%$. It suppresses B cells without affecting T cells. Anti-CD52 antibody has notable side effects, consistent with their action against both B and T cells (Countouriotis et al, 2002).

\section{TISSUE-SELECTIVE IMMUNOTHERAPY IN MELANOMA}

Like other melanoma differentiation antigens, tyrosinase-related proteins, TRP-1 and TRP-2, are expressed in melanoma, melanocytes, and retina (Wang et al, 1996). The immune responses to TRP-1 caused melanocyte destruction with depigmentation (vitiligo). The immune response against TRP-1 (anti-TRP-1 antibodies) could destroy both normal and malignant melanocytes (Overwijk and Restifo, 2000). The transfer, to patients with metastatic melanoma, of selected tumour-reactive $\mathrm{T}$ cells directed against overexpressed self-derived differentiation antigens led to regression of metastatic melanoma as well as to the onset of autoimmune melanocyte destruction (Dudley et al, 2002). Melanomas tend to become less pigmented in the course of malignant progression. Antimelanocyte therapy will likely facilitate this progression.

\section{EXPLOITING MELANIN BIOSYNTHESIS IN MELANOMA}

Unique tyrosine metabolic pathways in normal melanocytes can be exploited for selective killing of melanocytes, because melanogenesis is inherently toxic and uniquely expressed in melanocytic cells. Sulphur-containing substrate (tyrosine) analogues show selective cytotoxicity towards melanoma cell lines (Thomas et al, 1999). Nitrosoureas-containing tyrosine derivatives are evaluated as potential antimelanoma agents (Gadjeva, 2002). Effective melanocyte-toxic therapies must cause vitiligo. This side effect is a marker of therapeutic activity.

\section{THYROID CANCER: ANTIHORMONE THERAPY AND RADIOACTIVE IODINE}

The thyrotropin (TSH) hormone regulates proliferation and thyroid-specific gene expression (differentiation) of thyroid follicle cells. Early thyroid tumour development is correlated with mutation of alternative genes, including Ras and the TSH receptor (Wynford-Thomas, 1997). Thyrotropin suppression therapy (thyroxine application) of differentiated thyroid cancer is supported by most clinical studies (Pujol et al, 1996). In one-third of the cases following TSH-suppression therapy (and radioiodine therapy), dedifferentiation is observed, giving rise to tumours that are refractory to conventional treatment (Figure 2). Eventually, this may lead to the most malignant human tumour (anaplastic thyroid carcinoma) with a life expectancy of only a few months.

Although p53 mutations are present almost exclusively in poorly differentiated thyroid tumours (Wynford-Thomas, 1997), p53 mutation alone is not sufficient to drive progression of thyroid cancer to the aggressive anaplastic form (Wyllie et al, 1999).

Thyroid cancers are classified as papillary (82\%), follicular (8\%), medullary (9\%), and anaplastic (1\%). Anaplastic thyroid cancer

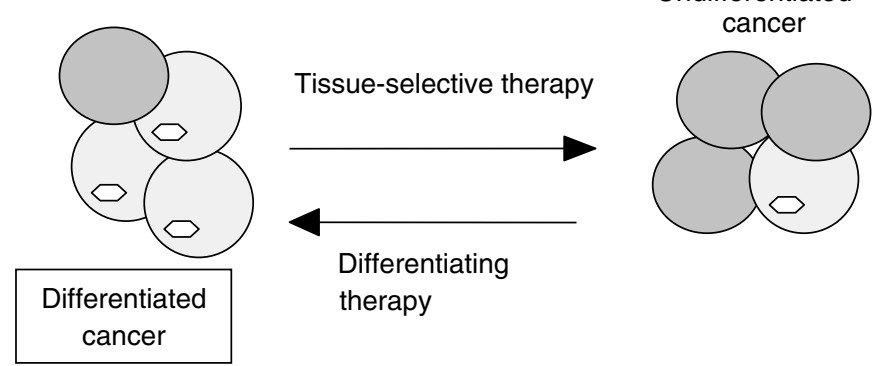

Figure 3 Alternating tissue-selective and differentiating therapies. Tissueselective and differentiating therapies complement each other. Tissueselective therapy kills differentiated cancer cells (cells having tissue-specific traits) but may promote undifferentiated cancer, which is insensitive to tissue-selective therapy. Then, differentiating therapy is needed. By reactivating tissue-specific genes, differentiating therapies may permit a new cycle of tissue-specific therapy.

cells are characterised by the absence of expression of thyroidspecific genes (TSH receptor, thyroglobulin, and thyroperoxidase). This results in their inability to incorporate radiactive iodine. Uptake of radioactive iodine, a normal function of thyroid cells, allows its accumulation 2000 over serum levels, thus killing the thyroid cell selectively. The prognosis of patients with papillary, the most differentiated thyroid cancer, is favourable and depends on tumour differentiation and the ability to take up radioactive iodine. The overall cure rate of radioiodine therapy (after 12 years) is $50 \%$ (papillary $65 \%$ vs follicular 23\%) (Pelikan et al, 1997). Lacking thyroid-specific functions dedifferentiated tumours are inaccessible to standard therapeutic procedures such as radioiodide therapy and thyrotropin suppression.

We can conclude that tissue-selective therapy (anti-TSH and radioactive iodine) is very effective in differentiated cancers but can select for undifferentiated cancer cells (Figure 2). Therefore, it is feasible to alternate tissue-selective and differentiating therapies (Figure 3).

\section{COMPLEMENTARY THERAPIES: DIFFERENTIATING AND TISSUE-SELECTIVE THERAPY}

Retinoic acid (RA) causes partial redifferentiation and increases iodine uptake in thyroid carcinoma cell lines. In clinical studies, about $40 \%$ of the patients responded to RA with an increased radioiodide uptake (Schmutzler and Koehrle, 2000; Schmutzler, 2001). Also, histone deacetylase (HDAC) inhibitor, FR901228, can modulate the expression of thyroid-specific genes. In follicular and aplastic thyroid cancer cell lines, a low concentration of FR901228 ( $1 \mathrm{ng} \mathrm{ml}^{-1}$ ) increased both thyroglobulin, the transporter for iodine and radioiodine accumulation (Kitazono et al, 2001). FR901228 was suggested to be used clinically in thyroid carcinomas that are unable to trap iodine as an adjunct to radioiodine therapy (Kitazono et al, 2001). In an anaplastic cell line, doxorubicin, a DNA-damaging drug, induced morphologically differentiated phenotype (Blagosklonny et al, 1998). It has been reported a conversion of non-iodine-concentrating thyroid carcinoma metastasis into iodine-concentrating foci after chemotherapy. A patient with metastatic papillary carcinoma was treated with cisplatin and doxorubicin. Repeat ${ }^{131} \mathrm{I}$ imaging after three cycles of chemotherapy showed significant ${ }^{131} \mathrm{I}$ uptake in previously non-iodine-concentrating lesions (Morris et al, 1997). Suppression of TSH and radioiodine are highly effective in differentiated thyroid cancer. On the other hand, they eventually select for undifferentiated cancer, insensitive to tissue-selective therapy. Differentiating therapies (RA, HDAC inhibitors, doxor- 
ubicin) may induce redifferentiation. By reactivating tissue-specific genes, differentiating therapy permits a new round of tissue-specific therapy (Figure 3 ). Tissue-selective and differentiating therapies complement each other (Figure 3 ).

\section{PERSPECTIVES OF TISSUE-SELECTIVE THERAPY}

Standard therapy of cancer is limited by its toxicity to normal cells (side effects). Logically, the goal of anticancer drug development is to exploit the differences between normal and cancer cells. Both hormonal therapy and immunotherapy were, historically, intended to target cancer cells. It is believed that 'the goal of monoclonal antibody therapy is to target specific cell surface antigens on malignant hematopoietic cells, while sparing normal cells and tissues' (Countouriotis et al, 2002). In reality, tissue-specific therapy will preferentially spare leukaemia cells, given their tendency towards dedifferentiation. For example, a number of $\mathrm{CD} 20$ receptors (one of the targets of immunotherapy) is 10 times lower on leukaemic cells than on normal B cells (Rossmann et al, 2001).

Tissue-selective therapy exploits peculiarities of normal tissues: incorporation of iodine by thyroid tissue, dependence on androgens by prostate tissue, expression of CD20 by lymphocytes, just to name a few. Potentials in the development of antitissue therapies are enormous, because differences between tissues are diverse and profound. A breast cell can produce milk, for instance, whereas a gastric cell is capable to secrete a gastric acid. These different biochemical pathways can be, in principle, targeted pharmacologically, by prodrugs, for instance. Research in biochemistry of normal tissues, not cancer cells, is needed to facilitate development of tissue-selective therapy.

By definition, tissue-selective therapy targets normal and cancer cells of the same tissue, without affecting other tissues. Targeting nonessential tissues results in few side effects. Even side effects of tamoxifen in breast cancer patients are caused by tissuenonselectivity of tamoxifen (e.g. effects on brain and endometrium). Furthermore, therapies against essential tissues (e.g. lymphocytes) are effective, even though they cause tissue-specific side effects (e.g. immunosuppression). To decrease side effects, novel therapy should target a subtissue instead of an entire tissue (e.g. a subpopulation of lymphocytes).

Not side effects but development of resistance, which may be accompanied by dedifferentiation, is an inherent limitation of tissue-selective therapy (Figure 2). Once relapsed, such cancer is resistant and aggressive. However, acquiring drug-resistance is a hallmark of all selective and effective therapies, including Gleevec for the therapy of CML and antibiotics for bacterial infections. This is predictable (Blagosklonny, 2002). Similarly, by killing differentiated cancer cells, which have tissue-specific traits, tissueselective therapy 'causes' dedifferentiation of cancer. Therefore, tissue-selective therapy should be complemented with differentiating therapy (Figure 3) and other therapeutic approaches (e.g. antiangiogenic and standard therapy). Then, by causing remissions without severe side effects, tissue-selective therapy may control cancer and even 'cure' cancer, given the limited human lifespan.

\section{REFERENCES}

Allen TM (2002) Ligand-targeted therapeutics in anticancer therapy. Nat Rev Cancer 2: $750-763$

Ashwell JD, Lu FW, Vacchio MS (2000) Glucocorticoids in T cell development and function. Annu Rev Immunol 18: 309-345

Bergan RC, Reed E, Myers CE, Headlee D, Brawley O, Cho HK, Figg WD, Tompkins A, Linehan WM, Kohler D, Steinberg SM, Blagosklonny MV (1999) A phase II study of high-dose tamoxifen in patients with hormone-refractory prostate cancer. Clin Cancer Res 5: 2366-2373

Blagosklonny MV (2002) STI-571 must select for drug-resistant cells but 'no cell breathes fire out of its nostrils like a dragon'. Leukemia 16: $570-572$

Blagosklonny MV, Giannakakou P, Wojtowicz M, Romanova LY, Ain KB, Bates SE, Fojo T (1998) Effects of p53-expressing adenovirus on the chemosensitivity and differentiation of anaplastic thyroid cancer cells. $J$ Clin Endocrinol Metab 83: 2516-2522

Countouriotis A, Moore TB, Sakamoto KM (2002) Cell surface antigen and molecular targeting in the treatment of hematologic malignancies. Stem Cells 20: $215-229$

Craft N, Chhor C, Tran C, Belldegrun A, DeKernion J, Witte ON, Said J, Reiter RE, Sawyers CL (1999) Evidence for clonal outgrowth of androgen-independent prostate cancer cells from androgen-dependent tumors through a two-step process. Cancer Res 59: 5030-5036

DeFeo-Jones D, Garsky VM, Wong BK, Feng DM, Bolyar T, Haskell K, Kiefer DM, Leander K, McAvoy E, Lumma P, Wai J, Senderak ET, Motzel SL, Keenan K, Van Zwieten M, Lin JH, Freidinger R, Huff J, Oliff A, Jones RE (2000) A peptide-doxorubicin 'prodrug' activated by prostate-specific antigen selectively kills prostate tumor cells positive for prostate-specific antigen in vivo. Nat Med 6: $1248-1252$

Dickey C (2002) Review reopens old disagreements. Nat Med 8: 1007

Dudley ME, Wunderlich JR, Robbins PF, Yang JC, Hwu P, Schwartzentruber DJ, Topalian SL, Sherry R, Restifo NP, Hubicki AM, Robinson MR, Raffeld M, Duray P, Seipp CA, Rogers-Freezer L, Morton KE, Mavroukakis SA, White DE, Rosenberg SA (2002) Cancer regression and autoimmunity in patients after clonal repopulation with antitumor lymphocytes. Science 298: $850-854$

Feldman BJ, Feldman D (2001) The development of androgen-independent prostate cancer. Nat Rev Cancer 1: $34-45$
Frankel AE (2002) Increased sophistication of immunotoxins. Clin Cancer Res 8: $942-944$

Gadjeva V (2002) Structure-based design of nitrosoureas containing tyrosine derivatives as potential antimelanoma agents. Eur J Med Chem 37: $295-300$

Hofseth LJ, Raafat AM, Osuch JR, Pathak D, Slomski CA, Haslam SZ (1999) Hormone replacement therapy with estrogen or estrogen plus medroxyprogesterone acetate is associated with increased epithelial proliferation in the normal postmenopausal breast. J Clin Endocrinol Metab 84: 4559- 4565

Kaspers GI, Pieters R, Van Zantwijk CH, Van Wering ER, Van Der DoesVan Den Berg A, Veerman AJ (1998) Prednisolone resistance in childhood acute lymphoblastic leukemia: vitro-vivo correlations and cross-resistance to other drugs. Blood 92: 259-266

Kitazono M, Robey R, Zhan Z, Sarlis NJ, Skarulis MC, Aikou T, Bates S, Fojo T (2001) Low concentrations of the histone deacetylase inhibitor, depsipeptide (FR901228), increase expression of the $\mathrm{Na}(+) / \mathrm{I}(-)$ symporter and iodine accumulation in poorly differentiated thyroid carcinoma cells. J Clin Endocrinol Metab 86: 3430-3435

Koivisto P, Visakorpi T, Rantala I, Isola J (1997) Increased cell proliferation activity and decreased cell death are associated with the emergence of hormone-refractory recurrent prostate cancer. J Pathol 183: 51-56

Merino R, Ding L, Veis DJ, Korsmeyer SJ, Nunez G (1994) Developmental regulation of the $\mathrm{Bcl}-2$ protein and susceptibility to cell death in $\mathrm{B}$ lymphocytes. EMBO J 13: $683-691$

Morris JC, Kim CK, Padilla ML, Mechanick JI (1997) Conversion of noniodine-concentrating differentiated thyroid carcinoma metastasis into iodine-concentrating foci after anticancer chemotherapy. Thyroid 7: $63-66$

Osborne CK, Zhao H, Fuqua SA (2000) Selective estrogen receptor modulators: structure, function, and clinical use. J Clin Oncol 18: $3172-3186$

Overwijk WW, Lee DS, Surman DR, Irvine KR, Touloukian CE, Chan CC, Carroll MW, Moss B, Rosenberg SA, Restifo NP (1999) Vaccination with a recombinant vaccinia virus encoding a 'self antigen induces autoimmune vitiligo and tumor cell destruction in mice: requirement for CD4(+) T lymphocytes. Proc Natl Acad Sci USA 96: 2982-2987 
Overwijk WW, Restifo NP (2000) Autoimmunity and the immunotherapy of cancer: targeting the 'self to destroy the 'other'. Crit Rev Immunol 20: $433-450$

Pelikan DM, Lion HL, Hermans J, Goslings BM (1997) The role of radioactive iodine in the treatment of advanced differentiated thyroid carcinoma. Clin Endocrinol (Oxf) 47: 713-720

Pujol P, Daures JP, Nsakala N, Baldet L, Bringer J, Jaffiol C (1996) Degree of thyrotropin suppression as a prognostic determinant in differentiated thyroid cancer. J Clin Endocrinol Metab 81: 4318-4323

Reese DM (2000) Choice of hormonal therapy for prostate cancer. Lancet 355: $1474-1475$

Rossmann ED, Lundin J, Lenkei R, Mellstedt H, Osterborg A (2001) Variability in B-cell antigen expression: implications for the treatment of B-cell lymphomas and leukemias with monoclonal antibodies. Hematol J 2: $300-306$

Schmutzler C (2001) Regulation of the sodium/iodide symporter by retinoids. Exp Clin Endocrinol Diab 109: $41-44$

Schmutzler C, Koehrle J (2000) Innovative strategies for the treatment of thyroid cancer. Eur J Endocrinol 143: 15-24

Song RX, Mor G, Naftolin F, McPherson RA, Song J, Zhang Z, Yue W, Wang J, Santen RJ (2001) Effect of long-term estrogen deprivation on apoptotic responses of breast cancer cells to 17beta-estradiol. J Natl Cancer Inst 93: $1714-1723$

Thomas PD, Kishi H, Cao H, Ota M, Yamashita T, Singh S, Jimbow K (1999) Selective incorporation and specific cytocidal effect as the cellular basis for the antimelanoma action of sulphur containing tyrosine analogs. $J$ Invest Dermatol 113: 928 -934

Tissing WJ, Meijerink JP, den Boer ML, Pieters R (2003) Molecular determinants of glucocorticoid sensitivity and resistance in acute lymphoblastic leukemia. Leukemia 17: 17-25

Van Houten N, Blake SF, Li EJ, Hallam TA, Chilton DG, Gourley WK, Boise LH, Thompson CB, Thompson EB (1997) Elevated expression of Bcl-2 and Bcl-x by intestinal intraepithelial lymphocytes: resistance to apoptosis by glucocorticoids and irradiation. Int Immunol 9: 945-953

Wang RF, Appella E, Kawakami Y, Kang X, Rosenberg SA (1996) Identification of TRP-2 as a human tumor antigen recognized by cytotoxic T lymphocytes. J Exp Med 184: $2207-2216$

Wolff JM, Tunn UW (2000) Intermittent androgen blockade in prostate cancer: rationale and clinical experience. Eur Urol 38: 365 - 371

Wyllie FS, Haughton MF, Rowson JM, Wynford-Thomas D (1999) Human thyroid cancer cells as a source of iso-genic, iso-phenotypic cell lines with or without functional p53. Br J Cancer 79: 1111-1120

Wynford-Thomas D (1997) Origin and progression of thyroid epithelial tumours: cellular and molecular mechanisms. Horm Res 47: $145-157$

Zietman AL, Dallow KC, McManus PA, Heney NM, Shipley WU (1996) Time to second prostate-specific antigen failure is a surrogate endpoint for prostate cancer death in a prospective trial of therapy for localized disease. Urology 47: 236-239 